This is a self-archived - parallel published version of this article in the publication archive of the University of Vaasa. It might differ from the original.

\title{
Leadership Competencies for Digital Transformation: Evidence from Multiple Cases
}

Author(s): Imran, Faisal; Shahzad, Khuram; Butt, Aurangzeab; Kantola, Jussi

Title: $\quad$ Leadership Competencies for Digital Transformation: Evidence from Multiple Cases

Year: $\quad 2020$

Version: Accepted manuscript

Copyright (C)2020 Springer. This is a post-peer-review, pre-copyedit version of an article published in Advances in Human Factors, Business Management and Leadership: Proceedings of the AHFE 2020 Virtual Conferences on Human Factors, Business Management and Society, and Human Factors in Management and Leadership, July 16-20, 2020, USA. The final authenticated version is available online at: http://dx.doi.org/o.1007/978-3-030-50791-6_11.

\section{Please cite the original version:}

Imran, F., Shahzad, K., Butt, A. \& Kantola, J. (2020). Leadership Competencies for Digital Transformation: Evidence from Multiple Cases. In: Kantola, J., Nazir, S. \& Salminen, V. (eds.) Advances in Human Factors, Business Management and Leadership: Proceedings of the AHFE 2020 Virtual Conferences on Human Factors, Business Management and Society, and Human Factors in Management and Leadership, July 16-20, 2020, USA, 81-87. Advances in Intelligent Systems and Computing, vol 1209. Cham: Springer. https://doi.org/10.1007/978-3-030-50791-6_11 


\title{
Leadership Competencies for Digital Transformation: Evidence from Multiple Cases
}

\author{
Faisal Imran ${ }^{1}$, Khuram Shahzad $^{1}$, Aurangzeab Butt ${ }^{1}$, Jussi Kantola ${ }^{1}$ \\ ${ }^{1}$ School of Technology and Innovation, University of Vaasa, Yliopistonranta 10, \\ 65100, Vaasa, Finland \\ \{Faisal.Imran, Khuram.Shahzad, Aurangzeab.Butt, Jussi.Kantola\}@uva.fi
}

\begin{abstract}
Digital transformation (DT) is disrupting industrial organizations, which require significant changes in their properties to remain competitive. This calls for strong leadership to drive this transformation. However, what leadership competencies are required to lead DT impactfully is unclear. Therefore, we seek to identify the key leadership competencies by employing a qualitative, grounded theory approach. By conducting interviews of ten DT experts from two hardcore industrial organizations, we highlight five key leadership competencies that industrial organizations need to develop in their leaders: digital vision, digital knowledge, failing fast, empowerment, and managing diverse teams. The results of this study will help industrial organizations to strategically prepare their leadership for the requirements of DT.
\end{abstract}

Keywords: Digital Transformation, Leadership, Competencies, Digitalization, Industry 4.0 .

\section{Introduction}

In this era of the fourth industrial revolution, industrial organizations require revolutionary changes to sustain themselves and remain competitive [1]. There are different factors behind these changes requirement, such as surging customer expectations and unprecedented competition, however, exponential technological development remains the biggest reason [2], [3]. To address this technological development, industrial organizations are radically transforming themselves to gain operational efficiency by introducing new digital technologies as well as by changing their social systems [4], [5]. However, industrial organizations require strong leadership at the helm [6] to lead this transformation impactfully. Strong leaders actively recognize when the change is required, understand the requirements for it, and foster an environment that supports the change [7]. Furthermore, leaders provide vision for the change from an existing state to a new improved state and prepare people to adapt enthusiastically to compete [7]. Moreover, they assess the change

\footnotetext{
* Primary Author
} 
hardiness, prepare for resistance, gain support for change, involve people in decisions that affect them, provide clarity regarding behavioral expectations, create opportunities to practice new skills, use the feedback process to monitor implementation, reward and reinforce both progress and success, and align systems to support the new and desired behaviors [8]. The same holds true for those leaders who are leading the change for digital transformation (DT).

DT is a process that aims to improve organizations by triggering significant changes to their properties through combinations of information, computing, communication, and connectivity technologies [5]. It helps industrial organizations to make a fundamental shift from a traditional organization (industrial economy based) to an modern organization (one suited for today's digital economy) [1], [9]. Moreover, DT enables industrial organizations to develop agility, collaboration, innovation, enhanced customer experience, streamlining operations, and new business models [1], [10]. However, it require organizations to take company-wide initiatives [11] to transform the culture, structure, strategy, business processes, and business models [2], [10]. Hence, DT is not just about the introduction of new technologies; rather, it is about taking holistic steps to transform overall organizational properties to reap the full benefits it offers. Therefore, organizational leadership must work accordingly to ensure optimization between these new technical and social systems [12], [13]. However, the literature shows that industrial organizations struggle to embrace the opportunities through DT [14]. This finding challenges organizational leadership to reinvent their competencies to lead DT in their organizations [5].

Leadership competencies are the knowledge, skills, abilities, and attributes that leaders must possess to perform their jobs proficiently [7]. The existing literature on leadership competencies and DT has mostly focused on certain profiles such as chief digital officers or chief technical officers [15], [16], who actually develop and lead DT programs in their organizations. However, the literature has ignored the competency requirements of functional level leaders that actually implement DT in practice. Moreover, the literature lacks an empirical study that explores the key competencies of functional level leaders. Therefore, our main objective is to explore the key competencies required of functional level leaders to lead DT impactfully in industrial organizations.

\section{Methodology}

Our research is based on a multiple case study design that examines the key competencies of organizational leadership for digital transformation [17]. As DT is an evolving phenomenon in the literature [18], [19], we therefore used qualitative methods to collect and analyze the data [20] to extract the key competencies of leadership required for DT. We chose two industrial organizations as case companies, based on methodological expediency [21]. Both case companies are hardcore engineering industrial organizations that were established during the second industrial revolution [9]. Moreover, both are already working intensively on DT. 
We relied on semi-structured interviews and publicly available documents of the case companies to identify the leadership competencies in question. We conducted in total ten interviews from experienced leaders who are leading DT in their functions. The interview transcripts compromised 170 pages and over 700 minutes of recordings. Furthermore, we used a grounded theory approach to analyze the data [22]. For this purpose, we used NVivo 12 for coding. In addition, we followed the data analysis technique of Gioia, Corley, \& Hamilton (2013) in which data is organized into concepts and thereafter themes are developed that facilitate the identification of leadership competencies.

\section{Results and Discussions}

In the analysis, five main competencies of leaders emerged that are critical for DT of industrial organizations. These five competencies are discussed in the following.

\section{Digital Vision}

The first step toward DT is having a strategic vision to lead it [23]. Vision in the context of DT is referred to in the literature as "Digital Vision" [11], [24]. Digital vision require leaders to look beyond existing strategies and previous procedures and envision the digital future of their organizations [11]. However, it requires leadership to align their actions with their vision and make it understandable for their subordinates. The director of DT stated the importance of vision, "The key role of leaders is to inspire their people with purposeful vision that can engage those people emotionally for DT." However, another Director of DT stressed the need for alignment between vision and action, "the capability of a leader is not just to have a vision but how he conveys that vision in an understandable and easy way to its people, so that they can buy his vision." The general manager of operational development explained this with an example, "If you want everybody to start using some digital tools and then you go with paper handouts, it's kind of not strengthening your message." Therefore, leaders need to provide a purposeful vision in their organization and implement it by designing actionable plans around this vision.

\section{Digital Knowledge}

Having the knowledge of digital tools and processes emerged as one of most important competences that leaders must have to lead DT. However, the interviewees emphasized that the leaders are not required to possess hardcore technical knowledge for this purpose; rather a good understanding of digital tools is enough. The director of DT explained, "I don't think they (leaders) should be expert in technology... what they should understand literally is how can a certain technology in broad terms impact our customers' business and our business." Similarly, the general manager of operational development noted, "you (leaders) don't need to be a coder...but you must understand how we can utilize a particular technology?" Another director of DT stated that "It is (technical competence) definitely essential...they don't need to know it from scratch...but at least one should understand the impact of these technologies and the potential of these technologies on the business." Some scholars also 
have reported similar views regarding this competence. For example, Singh and Hess (2017) [11] emphasized that the leaders must understand the information technology (IT) applications, as new products and services are based on IT. Petrucci and Rivera (2018) [25] reported how digital technologies can help leaders at work, e.g., utilizing digital technologies to enhance real-time feedback and to derive behavior change, performance improvements, and understand the complex flows. Based on these views, we argue that the leaders of DT must have a basic knowledge of these emerging new digital technologies, how these technologies can influence their businesses and operations, and how they can utilize these technologies to ensure the impactful DT of the incumbent organizations.

\section{Failing Fast}

Failing fast is one of the most frequently mentioned competencies by the interviewees. The literature as well as the interviewees have addressed the failing fast competence in relation to experimental learning, risk taking ability, using digital technologies in minimizing risk, and the fail and learn attributes of leaders [26]. Failing fast is an agile strategy that reflects the responsive timing of a failure within a given process [27]. The aim of failing fast is to recognize conditions which indicate a potential failure and then cease work on that task/project rather than investing more time and resources on it [28]. The vice president of open innovation explained, "leaders need to be able to go through with something (project/tasks) and then stop, analyze is it working? And then be able to adjust quickly if things are failing." The director of DT explained this competency by stating, "let's learn and fail together, and improve. That's what I been doing myself as a leader." Therefore, leaders must develop capabilities to fail and learn fast in order to save resources for their organizations, and digital technologies can play a vital role in achieving this purpose.

\section{Empowerment}

Empowerment, or the delegation of power toward those lower down the hierarchy, has emerged as another very important competency that is required to ensure impactful DT for industrial organizations. It helps in enhancing the meaningfulness of work, fostering participation in decision making, expressing confidence in high performance, and providing autonomy from bureaucratic constraints [29]. Almost every interviewee stressed the need of delegation of power for DT. The director of IoT stated, "Leadership needs to transform from power to empower... that you need to empower your people to take the decisions because what they are working on is so big and complex that if you think you as a leader can do that, you will be the bottleneck." Meanwhile, the director of DT explained, "We (as a leader) want everyone to feel empowered," and the senior director of global technology said, "You (as a leader) need to trust more and you need to empower more (for DT)". Therefore, by delegation of power, leaders can focus more on strategic aspects, as well as helping their teams to feel part of this whole transformation. 


\section{Managing Diverse Teams}

DT requires business and IT teams to work together to define, design, deliver, prioritize, implement, enhance, and discard new digital services and products [30]. Moreover, industrial organizations develop cross-functional teams [5] to bring different resources to one place in order to start different projects. In addition, DT has enabled employees to work in virtual teams [31]. Therefore, leaders need to develop this competency to manage such diverse teams through different mediums. The director of DT mentioned the need to align their teams first, "For me, the first thing is to create a clear purpose of our team...I arrange one hour meeting per week with each of them as building trust is very important in team management...you have to manage each team member differently." Director digital development added, "In order to deliver complex projects, you need to develop diverse teams, therefore leaders must have the capability of building networks quickly to gather required diverse resources." Hence, the competency of managing diverse teams effectively is very important for the leaders of this digital age. Figure 1 presents the research framework for this paper.

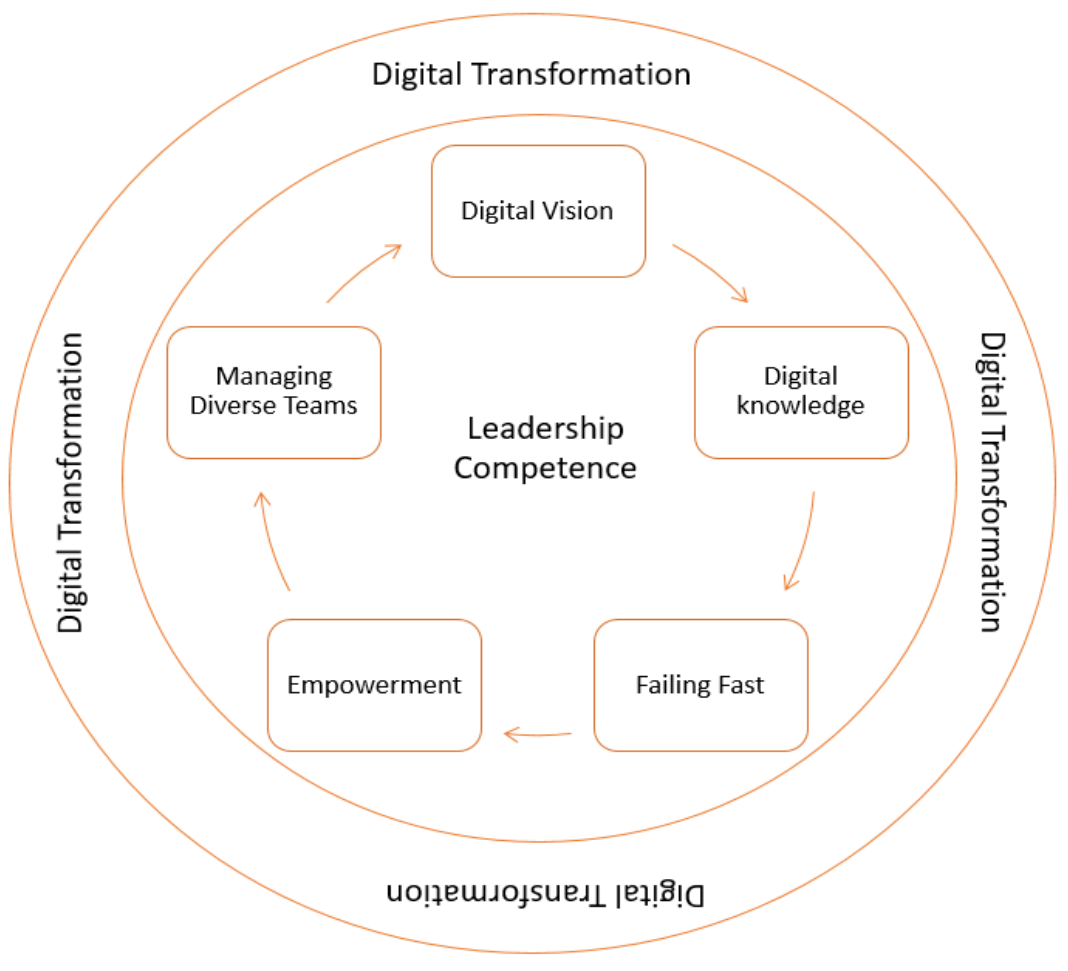

Figure 1. Research Framework 


\section{Conclusion}

DT is all about change, and leaders are the pioneers to implement these changes in industrial organizations. Moreover, DT is not only affecting industrial organizations but also changing the context and conditions for the leaders. Therefore, leaders must reinvent their competencies to drive DT successfully in their organizations. Leaders across the organization must have a clear vision about the possibilities that digital technologies offer and how to implement these. Along with this understanding, leaders need to develop their capabilities to try out new things and recognize fast whether it is working for them or not. In addition, they need to delegate their powers to reap the best out of DT. Moreover, they need the ability to manage diverse teams, as DT brings different functions and stakeholders to the same platforms to work together for the best outcome of their organization. Based on the identified leadership competencies, we argue that these will help industrial organizations to develop their leadership accordingly, enabling them to secure impactful DT. Moreover, to enhance the generalizability of these results, we recommend that future research includes more case organizations as well as interview participants.

\section{References}

1. Smet, A.D., Lurie, M., George, A.S.: Leading agile transformation: The new capabilities leaders need to build 21st-century organizations. McKinsey Co, October. pp. 27 (2018)

2. Agarwal, R., Johnson, S.L., Lucas, H.C.: Leadership in the Face of Technological Discontinuities: The Transformation of EarthColor. Commun. Assoc. Inf. Syst., 29 (2018)

3. Gilchrist, A.: Industry 4.0: The Industrial Internet of Things, Apress, Bangkok, Thailand (2016)

4. Hess, T.: Understanding Digital Transformation Strategy Formation: Insights from transformation strategy formation: Insights from Europe' s automotive industry (2019)

5. Vial, G.: Understanding digital transformation: A review and a research agenda. J. Strateg. Inf. Syst., vol. 28(2), pp. 118-144 (2019)

6. Kane, G.C., Phillips, A.N., Copulsky, J., Andrus, G.: How Digital Leadership Is(n't) Different: Leaders must blend traditional and new skills to effectively guide their organizations into the future. MIT Sloan Manag. Rev., 60(3), pp. 34-39 (2019)

7. Das, A., Kumar, V., Kumar, U.: The role of leadership competencies for implementing TQM: An empirical study in Thai manufacturing industry. Int. J. Qual. Reliab. Manag., 28(2), pp. 195219 (2011)

8. Gebelein, S.H.: Leadership Competency. Leadersh. Excell., 18(3), pp. 10 (2001)

9. Imran, F., Kantola, J.: Review of industry 4.0 in the light of sociotechnical system theory and competence-based view: A future research agenda for the evolute approach. Adv. Intell. Syst. Comput. 783, pp. 118-128 (2018)

10. Sainger, G.: Leadership in Digital Age: A Study on the Role of Leader in this Era of Digital Transformation. Int. J. Leadersh., 6(1), pp. 1-6 (2018)

11. Singh, A., Hess, T.: How Chief Digital Officers Promote the Digital Transformation of their Companies. MIS Q. Exec. 16(2), pp. 1-17 (2017)

12. Mumford, E.: A Socio-Technical Approach to Systems Design. Requir. Eng., 5(2), pp. 125-133 (2000) 
13. Barone, G.: Being a smart leader in the digital age. May, pp. 16-18 (2019)

14. Loebbecke, C., Picot, A.: Reflections on societal and business model transformation arising from digitization and big data analytics: A research agenda. J. Strateg. Inf. Syst., 24(3), pp. 149-157 (2015)

15. Reck, F., Fliaster, A.: Four profiles of successful digital executives four types of effective digital executives in business organizations. MIT Slo. Mgt. Rev. (2019)

16. Wade, M., Obwegeser, N.: How to choose the right digital leader for your company," MIT Sloan Manag. Rev. (2019)

17. Eisenhardt, K.M.: Building theories from case study research. Acad of Manag. Rev., 14(4), pp. 532-550 (1989)

18. Matthews, B., Ross, L.: Research methods. A practical guide for the social sciences. Pearson Longman, Harlow, UK (2010)

19. Hesse, A.: Digitalization and leadership - How experienced leaders interpret daily realities in a digital world. Proc. 51st Hawaii Int. Conf. Syst. Sci., (2018)

20. Yin, R.: Case study research: Design and methods. Sage Publications, London, (2003)

21. Huberman, A., Miles, M., Janet Ward, S.: Increasing the generalizability of qualitative research. Ín The Qual. Reser. Comp. (2012)

22. Gioia, D.A., Corley, K.G., Hamilton, A.L.: Seeking Qualitative Rigor in Inductive Research: Notes on the Gioia Methodology. Organ. Res. Methods, 16(1), pp. 15-31 (2013)

23. Larjovuori, R.L., Bordi, L., Heikkilä-Tammi, K.: Leadership in the digital business transformation. ACM Int. Conf. Proceeding Ser., no. October, pp. 212-221 (2018)

24. Fitzgerald, M., Kruschwitz, N., Bonnet, D., Welch, M.: Embracing Digital Technology: A New Strategic Imperative | Capgemini Consulting Worldwide. MIT Sloan Manag. Rev., 55(1), pp. 113 (2013)

25. Petrucci T., Rivera, M.: Leading Growth through the Digital Leader. J. Leadersh. Stud., 12(3), pp. 53-56 (2018)

26. Colbert, A., Yee, N., George, G.: The Digital Workforce and the Workplace of the Future. Acad. Manag. J., 59(3), pp. 731-739 (2016)

27. Khanna, R., Guler, I., Nerkar, A.: Fail often, fail big, and fail fast? Learning from small failures and R\&D performance in the pharmaceutical industry. Acad. Manag. J., 59(2), pp. 436-459 (2016)

28. Friend, S.B., Ranjan, K.R., Johnson, J.S.: Fail fast, sell well: The contingent impact of failing fast on salesperson performance. Ind. Mark. Manag., 82, pp. 265-275 (2019)

29. Ahearne, M., Mathieu, J., Rapp, A.: To empower or not to empower your sales force? An empirical examination of the influence of leadership empowerment behavior on customer satisfaction and performance. J. Appl. Psychol., 90(5), pp. 945-955 (2005)

30. Sebastian, I.M., Mocker, M., Ross, J.W., Moloney, K.G., Beath, C., Fonstad, N.O.: How Big Old Companies Navigate Digital Transformation. MIS Q. Exec., 16(3), pp. 197-213 (2017)

31. Schwarzmüller, T., Brosi, P., Duman, D., Welpe, I.M.: How Does the Digital Transformation Affect Organizations? Key Themes of Change in Work Design and Leadership. Manag. Revu, vol. 29(2), pp. 114-138 (2018) 